\title{
Non-ulcer dyspepsia and short term De-Nol therapy: a placebo controlled trial with particular reference to the role of Campylobacter pylori
}

\author{
T ROKKAS, C PURSEY, E UZOECHINA, L DORRINGTON, $N$ A SIMMONS, \\ $M$ I FILIPE, AND G E SLADEN \\ From the Gastroenterology Unit, Division of Medicine, Dept of Clinical Bacteriology and Histopathology, \\ UMDS Guy's and St Thomas' Hospitals, London
}

SUMmary This double blind randomised study tested the effectiveness of colloidal bismuth subcitrate (De-Nol) in non-ulcer dyspepsia (NUD) and if any benefit is associated with clearance of Campylobacter pylori $(C$ pylori) from the gastric mucosa. Sixty six patients with dyspepsic symptoms, normal abdominal ultrasound, and upper GI endoscopy, were randomly allocated to placebo or De-Nol for eight weeks. Antral biopsies were taken for bacteriological and histological examination, and endoscopies and clinical questionnaires were administered before and after treatment. Fifty two patients ( 25 on De-Nol and 27 on placebo) completed the trial. De-Nol cleared $C$ pylori from 10 of the $12 C$ pylori positive patients $(83 \cdot 3 \%)$, whereas placebo did not clear $C$ pylori from any of the eight $C$ plyori positive patients $(\mathrm{p}<0.01)$. In patients receiving De-Nol gastritis improved $(\mathrm{p}<0.01)$ and symptomatic response was better $(p<0 \cdot 001)$ compared with placebo. In the placebo group seven of the $19 C$ pylori negative patients became positive: this was associated with significant deterioration of symptoms, a phenomenon not seen in the De-Nol treated group.

Colloidal bismuth subcitrate (De-Nol) has been shown to be an effective treatment for peptic ulcer disease $^{1-3}$ and studies suggest that it leads to longer remissions than have been previously reported for the $\mathrm{H}_{2}$ antagonists. ${ }^{3-6}$

In 1982 a new spiral Gram-negative organism similar to that of the genus campylobacter was isolated from the gastric mucosa of patients with gastritis.' The new organisms were originally called Campylobacter-like organisms (CLO), later Campylobacter pyloridis (C pyloridis) ${ }^{89}$ and now Campylobacter pylori ( $C$ pylori).$^{10} \mathrm{~A}$ strong association between gastritis and the presence of $C$ pylori has recently been established ${ }^{11-13}$ and there is evidence to suggest that $C$ pylori may be pathogenic. ${ }^{14}$ De-Nol has been reported to have antibacterial properties and to clear $C$ pylori from the gastric mucosa with a corresponding restoration of epithelial morphology..$^{15} 16$

Address for correspondence: G E Sladen, DM, FRCP, Gastroenterology Unit, Guy's Hospital, London SE1 9RT.

Received for publication 4 March 1988.
Non-ulcer dyspepsia (NUD) is poorly understood and often present in association with gastritis. ${ }^{17}$ Among patients undergoing gastroscopy approximately half with NUD have a gastric mucosa colonised by $C$ pylori and there is evidence suggesting that it may play a pathogenic role in NUD. ${ }^{18}$ Little is known, however, about the value of De-Nol in the treatment of NUD and therefore we undertook a placebo controlled trial to examine whether De-Nol is effective in the treatment of NUD and whether any benefit is associated with the clearance of $C$ pylori from the gastric mucosa.

\section{Methods}

PATIENTS

Over the past 18 months 66 patients ( 42 men, mean age $39 \cdot 1$ years, range 18-64) were included in the trial. The series comprised consecutive patients with upper GI dyspeptic symptoms, whose gastroscopy was either normal or showed minor inflammatory features in the antrum (usually patchy erythema), 
who conformed to the inclusion criteria and who gave their informed consent to take part in the trial. Patients were excluded from the study if they had peptic ulceration, neoplasm, erosive or ulcerative oesophagitis, recently consumed non-steroidal antiinflammatory drugs (NSAID), been treated with $\mathrm{H}_{2}$ blockers within seven days of endoscopy, debilitating disease, previous gastric surgery, renal insufficiency, pregnancy or breast feeding, or were unable to cooperate. No patient had prominent bowel symptoms suggesting the irritable bowel syndrome. The study was approved by Guy's Medical School ethical committee.

\section{STUDY DESIGN}

After gastroscopy patients were questioned by one of the authors (TR) about the presence of dyspeptic symptoms - that is, epigastric pain, nausea, vomiting, heartburn, halitosis, postprandial bloating, and flatulence. They were also questioned about smoking and alcohol consumption. The patient's overall well being was quantified using a scale from 0 to 100 , with 0 representing no symptoms and 100 representing severe, unbearable symptoms. Subsequently the patients were randomly allocated to eight weeks treatment with either De-Nol (two tablets to be taken twice daily, half an hour before breakfast and dinner with a drink of water - that is, a total dose of $480 \mathrm{mg}$ ) or matching placebo (two tablets to be taken twice daily, half an hour before meals with water). Blindness was attempted by providing medication and instructions in identical sealed boxes and only a minority remarked on changes of taste or faecal colour (see side effects). In addition all patients were given a supply of antacid tablets (Gelusil) for symptomatic relief and a diary on which to record daily the presence or absence of epigastric pain, its duration, and the number of antacid tablets taken. In addition they were given instructions to avoid drugs such as NSAID, antibiotics, and $\mathrm{H}_{2}$-blockers during the trial. At this stage an abdominal ultrasound was arranged for all patients and those who were found to have pathology to which the dyspeptic symptoms

Table Characteristics of 52 patients randomly assigned to receive De-Nol or placebo

\begin{tabular}{llll}
\hline & $\begin{array}{l}\text { De-Nol } \\
\text { group }\end{array}$ & $\begin{array}{l}\text { Placebo } \\
\text { group }\end{array}$ & $\begin{array}{l}\text { Statistical } \\
\text { significance }\end{array}$ \\
\hline Patients (n) & 25 & 27 & NS \\
Age (mean (SE)) & $39(2 \cdot 7)$ & $38 \cdot 7(2 \cdot 1)$ & NS \\
Sex (M:F) & $18: 7$ & $16: 11$ & NS \\
Smokers & 12 & 11 & NS \\
Daily alcohol consumers & 12 & 16 & NS \\
$\begin{array}{l}\text { Cpylori +ve: } C \text { pylori - ve ratiolion } \\
\text { Symptom score before }\end{array}$ & $59.76(3 \cdot 31) 55 \cdot 88(4 \cdot 5)$ & NS \\
\multicolumn{1}{c}{ treatment } & & & \\
\hline
\end{tabular}

could be attributed, such as gall stones and pancreatic disease, were withdrawn from the study. Subsequently the patients were seen in the clinic at four weeks for evaluation of possible side effects. At the end of the trial (eight weeks) all patients were reevaluated clinically using the same questionnaire and scale of well being and they returned the diary. Unused trial tablets were then counted to assess compliance. Subsequently all patients were endoscoped, by the same person when possible (GES), within 48 hours of finishing the treatment. At endoscopy antral biopsies were taken for bacteriological and histological examination. Routine cleansing between cases included six to seven minutes exposures to either Cidex or the detergent/antiseptic Teepol, depending on the endoscope used. Biopsy forceps were sterilised in Cidex.

\section{BLOOD BISMUTH MEASUREMENT}

At the end of the study blood concentrations of bismuth were determined by atomic absorption spectrophotometry. Measurements were made by an independent laboratory and details of the method have been published elsewhere. ${ }^{19}$

\section{BACTERIOLOGY AND HISTOPATHOLOGY}

The methods have been described in our earlier paper. ${ }^{18}$ The activity of gastritis was assessed by the same examiner (MIF) and graded from 0 to 3 depending on the number of neutrophils - that is, 0 for normal histology, 1 for mild, 2 for moderate, and 3 for severe inflammation.

\section{STATISTICAL ANALYSIS}

Results were expressed as mean (SE). Chi squared test with Yates' correction, Fisher's exact test, the Wilcoxon's test for paired data and the Mann Whitney $U$ test were used for statistical analysis where appropriate. A $p$ value less than 0.05 was considered as significant.

\section{Results}

\section{PATIENTS}

Of the 66 patients who were initially recruited, 52 completed the trial. Of the 14 remaining patients (seven on De-Nol, seven on placebo), two (one on placebo, one on De-Nol) were excluded because their abdominal ultrasound showed calculi in their gall bladder, one on placebo because he developed severe diarrhoea and it was thought that the treatment should be stopped, six (two on De-Nol, four on placebo) were excluded for non-compliance with the dosage requirements and five (four on De-Nol, one on placebo) did not attend for a second gastroscopy. Of the 52 patients who completed the trial 25 were on De-Nol and 27 on placebo. The two groups did not 
differ significantly as far as age, sex, alcohol consumption, presence of $C$ pylori, and symptom score before treatment were concerned (Table).

\section{PYLORI CLEARANCE WITH TREATMENT}

De-Nol succeeded in clearing $C$ pylori from 10 $(83.3 \%)$ of the $12 C$ pylori positive patients $\left(\chi^{2}=8\right.$, $\mathrm{p}<0.01)$. In contrast placebo did not clear $C$ pylori from any of the eight $C$ pylori positive patients.

\section{SYMPTOMATIC RESPONSE}

There was good response to treatment in the De-Nol group $(n=25)$, in that the symptom score before treatment $(59.76(3.31))$ was significantly worse $(\mathrm{p}<0.001)$ than after treatment $(32.76(4 \cdot 76))$ (Fig. 1). This improvement was associated with a good symptomatic response in the $C$ pylori positive subgroup $(n=12)$ in which the symptom score before treatment $(63.5(4 \cdot 11))$ was significantly worse than after treatment $(16(5) \mathrm{p}<0.001)$. In this subgroup De-Nol completely resolved the symptoms in five of $12(41.6 \%)$ patients. The $C$ pylori negative patients $(n=13)$ did not show any improvement in that the symptom scores before treatment $(56.3(5))$ were similar to those after treatment (48.23 (5)).

In contrast with De-Nol, placebo did not succeed in improving symptoms in the whole group $(n=27)$,

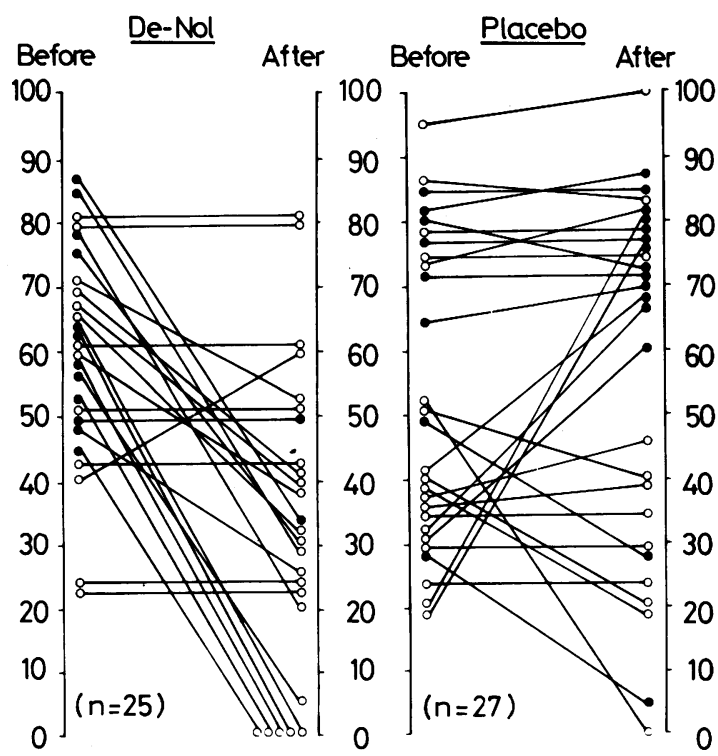

Fig. 1 Patients'symptom score before and after treatment in De-Nol and placebo groups. Dots and open circles represent $\mathrm{C}$ pylori positive, and negative patients respectively. De-Nol group: whole group: $p<0.001 ; \mathrm{C}$ pylori +ve pts $(n=12)$ : $p<0.001$, C pylori -ve pts $(n=13)$ NS. Placebo group: whole group: $N S, \mathrm{C}$ pylori +ve pts $(n=8): N S$; C pylori -ve pts $(n=19):$ NS; C pylori -ve pts who became +ve after treatment $(n=7): p<0.02$. in that the symptom scores before treatment $(55.88$ (4.5)) were similar to those after treatment (53.92 (5.23)). In the subgroup of $C$ pylori positive patients $(\mathrm{n}=8)$ scores before treatment $(66.87(6.48))$ did not differ from those after treatment $(61(10 \cdot 1))$ and similarly in the subgroup of $C$ pylori negative patients $(n=19)$ scores before and after treatment did not differ $(47(5 \cdot 3) v 53.57$ (6.31) NS) (Fig. 1).

In the De-Nol and placebo subgroups of $C$ pylori positive patients, comparison of weekly pain free days showed that these two groups did not differ significantly for the first three weeks and became significant thereafter, reaching highly significant levels by the end of treatment (Fig. 2).

The consumption of antacids during the trial for pain relief in the two subgroups of $C$ pylori positive patients was similar for the first three weeks and became significant during the remaining weeks (Fig. 3).

In the whole group of 66 patients there was a significant association between $C$ pylori and postprandial bloating $\left(\chi^{2}=5 \cdot 33, p<0 \cdot 05\right)$. In the subgroup of $C$ pylori positive patients De-Nol abolished postprandial bloating in eight of 10 patients with this symptom $(p=0.002)$ whereas placebo did not.

\section{HISTOLOGICAL RESPONSE}

In the whole group of patients De-Nol significantly improved gastric mucosal histology (activity before treatment $1.12(0.22) v 0.56(0.15)$ after treatment, $\mathrm{p}<0.001)$ and this was due to the fact that 10 of the 12 $C$ pylori positive patients who became negative after treatment had significant improvement in their histology (activity before treatment $2.08(0.20) v 1.08$ $(0 \cdot 22)$ after treatment, $\mathrm{p}<0.001)$ (Fig. 4). In detail three of these 10 patients $(30 \%)$ had complete morphological restoration after treatment and seven (70\%) had significant improvement. The other two $C$ pylori positive patients who did not change histology after treatment were those in whom De-Nol did not clear $C$ pylori.

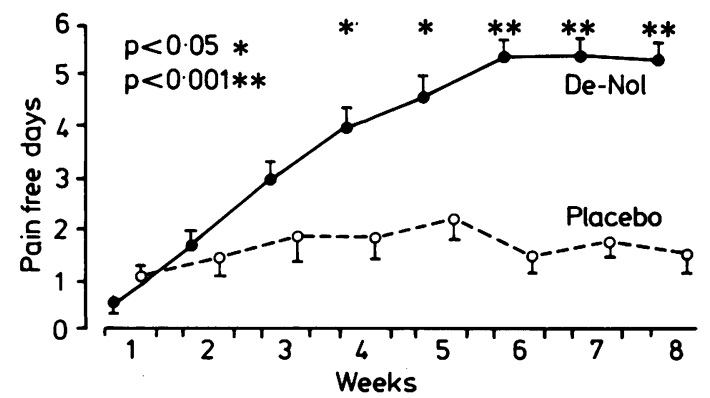

Fig. 2 Weekly pain free days in NUD C pylori positive patients receiving De-Nol $(n=12)$ or placebo $(n=8)$ during eight weeks treatment. Values are mean (SE). 
In contrast with De-Nol, placebo did not succeed in improving the histological picture either in the whole group (activity before treatment $1.03(0 \cdot 18) v$ $1.22(0 \cdot 18)$ after treatment, NS), or in the subgroup of the $C$ pylori positive patients (activity before treatment $2(0.26) v 1.62(0.32)$ after treatment, NS) (Fig. 4).

\section{PATIENTS WHO BECAME C PYLORI POSITIVE DURING TREATMENT}

In the placebo group seven of the 19 Cpylori negative patients before treatment $(36 \cdot 8 \%)$ were found to have $C$ pylori positive cultures at the end of treatment. No $C$ pylori negative patients became positive in the De-Nol group and the difference between the two groups in $C$ pylori negative patients who became positive was significant $\left(\chi^{2}=7 \cdot 1, p<0 \cdot 01\right)$. In these seven patients the symptom scores after treatment $(72.85(2.72))$ were significantly worse $(\mathrm{p}<0.02)$ than those before treatment $(41.85(0.93))$ (Fig. 1). Similarly, in this group of patients, histology after treatment $(1.85(0.26))$ was significantly worse $(\mathrm{p}<0.02)$ than before treatment $(0.85(0.26))$ (Fig. 4).

At the end of their treatment with placebo all seven patients were given De-Nol in open trial.

\section{BISMUTH BLOOD CONCENTRATIONS}

Serum bismuth concentrations at the end of treatment were measured in the first 46 patients who completed the trial. These consisted of 23 patients from the De-Nol group and 23 patients from the placebo group. All measurements were well below the level of $50 \mu \mathrm{g} / .^{20}$

\section{SIDE EFFECTS}

No significant side effects were encountered. One patient in the De-Nol group complained of transient nausea and another two in the same group complained of an unpleasant lingering taste after chewing

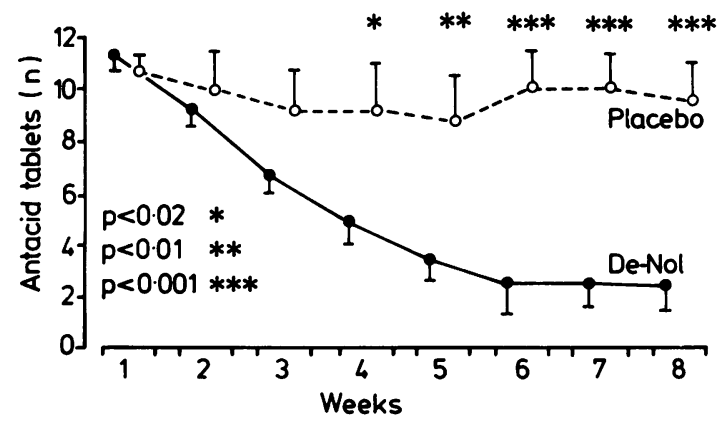

Fig. 3 Number of antacid tablets taken per week in NUD C pylori positive patients receiving $\mathrm{De}-\mathrm{Nol}(n=12)$ or placebo $(n=8)$ during eight weeks treatment. Values are mean (SE).

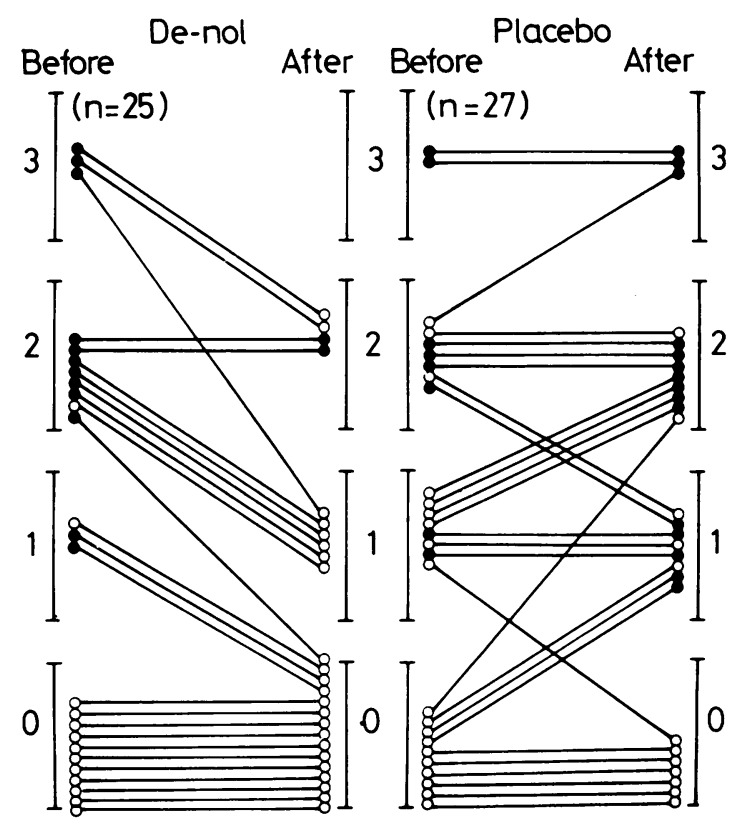

Fig. 4 Patients' histology before and after treatment in De-Nol and placebo groups. Dots and open circles represent $\mathrm{C}$ pylori positive and negative patients respectively. De-Nol group: whole group: $p<0.001$; C pylori +ve pts $(n=12)$ : $p<0.001 ; C$ pylori - ve pts $(n=13)$ : NS. Placebo group: whole group: NS; C pylori+ve pts $(n=8): N S$; C pylori -ve pts $(n=19)$ : NS; C pylori -ve pts who became +ve after treatment $(n=7 ;: p<0 \cdot 02$.

the tablets. None of these three patients considered this as an unacceptable problem and did not discontinue the medication. Two others mentioned that their faeces were very dark. One patient in the placebo group developed severe diarrhoea and it was thought that the treatment should be stopped.

\section{Discussion}

Non-ulcer dyspepsia is a poorly understood syndrome often present in association with gastritis ${ }^{17}$ and among patients undergoing gastroscopy approximately half with NUD have a gastric mucosa colonised by $C$ pylori. ${ }^{14}$ We confirmed this in an earlier study, ${ }^{18}$ which included many but not all the patients reported here but which was not concerned with treatment. Our studies also confirmed the strong association between the presence of $C$ pylori in the gastric mucosa and histological gastritis. ${ }^{.1-13}$ Several investigators have recently successfully used bismuth salts and other antimicrobial agents in the treatment of $C$ pylori associated gastritis ${ }^{1516}$ and in these studies clearance from the gastric mucosa was accompanied by resolution or significant improvement of histological gastritis. 
In our study De-Nol, as opposed to placebo, was successful in clearing $C$ pylori from the gastric mucosa of patients with positive cultures with a significant improvement of gastritis. This strengthens the possibility that $C$ pylori may play a role in the pathogenesis of NUD.

We also found a significant symptomatic improvement in the De-Nol group as opposed to placebo. This improvement was because of the highly significant amelioration of symptoms in the $C$ pylori positive patients who obtained relief from epigastric pain by the end of the third week of therapy and reached high levels of statistical significance by the end of treatment. This was accompanied by a significant reduction in antacid consumption which started at the end of the third week and became highly significant by the end of treatment. On the contrary the $C$ pylori negative patients, the majority of whom had normal histology, did not experience symptomatic improvement.

In this study we confirmed a significant association between $C$ pylori and postprandial bloating ${ }^{18}$ and found that De-Nol as opposed to placebo abolished this symptom in a significant number of patients in parallel with $C$ pylori clearance. This strongly suggests that $C$ pylori infection was responsible for postprandial bloating and this might be the result of $C$ pylori producing urease which would liberate carbon dioxide from urea present in the gastric mucosa. ${ }^{1821}$

The antimicrobial activity of bismuth salts ${ }^{15}$ or their mucosal protective effect ${ }^{22}$ could explain the effectiveness of De-Nol in the $C$ pylori positive patients. Studies of gastric biopsies by electron microscopy ${ }^{23}$ have shown that bismuth salts coat the $C$ pylori present in the gastric crypts and this is followed by swelling and lysis of the bacteria. This proves that bismuth salts penetrate the mucus layer and reach the gastric crypts in sufficient concentrations to kill $C$ pylori. On the other hand sucralfate, which is a gastric mucosal protective agent, ${ }^{24}$ is not active against $C$ pylori ${ }^{25}$ and does not clear it from the gastric mucosa or have any effect on histological gastritis. ${ }^{26}$ The ineffectiveness of a purely mucosal protective agent to improve gastritis strongly suggests that it is the antimicrobial activity of De-Nol that is important.

In this study seven $C$ pylori negative patients receiving placebo were found to be positive at the end of treatment and this change from negative to positive status was associated with significant deterioration in their symptoms and gastritis which stresses the pathogenic role of this organism as suggested elsewhere..$^{14}$ Five of these seven patients had gastritis initially and may have been colonised by $C$ pylori which was for some reason undetected. It is also possible that these patients were infected by
C pylori contaminated fibreoptic endoscopes. The symptomatic deterioration supports the latter explanation. The efficacy of Teepol and Cidex against $C$ pylori requires formal study. The fact that no $C$ pylori negative patients in the De-Nol group became positive stresses the effectiveness of this drug against $C$ pylori.

No serious side effects were observed with De-Nol and the bismuth levels at the end of treatment were well below the therapeutically acceptable upper limits. ${ }^{20}$ This confirms that De-Nol is a safe drug as stressed elsewhere. ${ }^{27}$

In conclusion, this study shows that short term DeNol treatment, as opposed to placebo, is successful in treating symptoms and healing the gastritis in NUD. In the $C$ pylori positive group in particular, De-Nol successfully cleared $C$ pylori from the gastric mucosa with significant improvement of symptoms and associated gastritis. This is in agreement with studies on NUD C pylori positive patients reported by others in abstract form. ${ }^{28}{ }^{29}$ Because endoscopy is unreliable for detecting gastritis in NUD patients ${ }^{1730-34}$ its main value is in obtaining specimens for histological and bacteriological processing and when cultures are positive for $C$ pylori, De-Nol administration is recommendable. It remains to be established whether the clearance of $C$ pylori and the associated histological and symptomatic improvement persists after a short course of De-Nol.

We are grateful to Gist-Brocades (Great Britain) Ltd, West Byfleet, Surrey, for supplying De-Nol and placebo. This study was presented in part at The American Gastroenterological Association (Rokkas et al, Gastroenterology 1987; 92: 1599) and at the British Society of Gastroenterology (Rokkas et al, Gut 1987; 28: A1337).

\section{References}

1 Tytgat GNJ, Van Bentem N, Van Olffen G, Dekker W, Rutgeerts L, De-Boer J. Controlled trial comparing colloidal bismuth subcitrate tablets, cimetidine and placebo in the treatment of gastric ulceration. Scand $J$ Gastroenterol 1982; 17 (suppl 80): 31-8.

2 Hamilton I, Worsley BW, O'Connor HJ, Axon ATR. The effects of tripotassium dicitratobismuthate tablets or cimetidine in the treatment of duodenal ulcer. Gut 1983; 24: 1148-51.

3 Bianchi Porro G, Lazzaroni M, Petrillo M, DeNicola C. Relapse rates in duodenal ulcer patients formerly treated with bismuth subcitrate or maintained with cimetidine. Lancet 1984; ii: 698.

4 Martin DF, Hollanders D, May SJ, Ravenscroft MM, Tweedle DE, Miller JP. Difference in relapse rates of duodenal ulcer after healing with cimetidine or tripotassium dicitratobismuthate. Lancet 1981; i: 7-10. 
5 Lee FI, Samloff IM, Hardman M. Comparison of tripotassium dicitratobismuthate tablets with ranitidine in healing and relapse of duodenal ulcers. Lancet 1985; i: 1299-302.

6 Hamilton I, O'Connor HJ, Wood NC, Bradbury NC, Axon ATR. Healing and recurrence of duodenal ulcer after treatment with tripotassium dicitrate bismuthate (TDB) tablets or cimetidine. Gut 1986; 27: 106-10.

7 Warren JR, Marshall BJ. Unidentified curved bacilli on gastric epithelium in active chronic gastritis. Lancet 1983; i: 1273-5.

8 Marshall BJ, Royce H, Annear DI, et al. Original isolation of Campylobacter pyloridis from human gastric mucosa. Microbios Letters 1984; 25: 83-8.

9 Anonymous. Validation of publication of new names and new combinations previously effectively published outside the IJSB. Int J Syst Bacteriol 1985; 35: 223-5.

10 Marshall BJ, Goodwin CS. Revised nomenclature of Campylobacter pyloridis. Int J Syst Bacteriol 1987; 37: 68.

11 Jones DM, Lessels AM, Eldridge J. Campylobacter like organisms on the gastric mucosa: culture, histological and serological studies. J Clin Pathol 1984; 37: 1002-6.

12 Marshall BJ, Warren JR. Unidentified curved bacilli in the stomach of patients with gastritis and peptic ulceration. Lancet 1984; ii: 1311-5.

13 McNulty CAM, Watson DM. Spiral bacteria of the gastric antrum. Lancet 1984; i: 1068-9.

14 Marshall BJ, McGechie DB, Rogers PA, Glancy RJ. Pyloric campylobacter infection and gastroduodenal disease. Med J Aust 1985; 142: 439-44.

15 McNulty CAM, Gearty JC, Crump B, et al. Campylobacter pyloridis and associated gastritis: investigator blind, placebo controlled trial of bismuth salicylate and erythromycin ethylsuccinate. $\mathrm{Br} \mathrm{Med} J$ 1986; 293: 645-9.

16 Tytgat GNJ, Rauws EAJ, Langenberg ML, Houthoff HJ. Campylobacter pyloridis: The Amsterdam study. Dig Dis Sci 1986; 31 (suppl): 149S.

17 Toukan AU, Kamal MF, Amr SS, Arnaout MA, AbuRomiyeh AS. Gastroduodenal inflammation in patients with non-ulcer dyspepsia. Dig Dis Sci 1983; 30: 313-20.

18 Rokkas T, Pursey C, Uzoechina E, et al. Campylobacter pylori and non-ulcer dyspepsia. Am J Gastroenterol 1987; 82: 1149-52.

19 Rooney RC. Determination of bismuth in blood and urine. Analyst 1976; 101: 749-52.

20 Hillemand $\mathbf{P}$, Palliere $\mathbf{M}$, Laquais $\mathrm{B}$, Bouvet $\mathrm{P}$. Traitment bismuthique et bismuthemie. Sem Hôp Paris 1977; 53: 1663-9.

21 Goodwin CS, Armstrong JA, Marshall BJ. Campylo- bacter pyloridis, gastritis and peptic ulceration. J Clin Pathol 1983; 39: 353-65.

22 Konturek SJ, Radecki T, Piastucki I, Drozdowicz D. Studies on the gastroprotective and ulcer-healing effects of colloidal bismuth subcitrate. Digestion 1987; 37 (suppl 2): 8-15.

23 Marshall BJ, Armstrong JA, McGechie DB, Francis GJ. The antibacterial action of bismuth: early results of antibacterial regimens in the treatment of duodenal ulcer. In: Pearson AD, Skirrow MB, Lior H, Rowe B, eds. Campylobacter III: proceedings of the third international workshop on campylobacter infections, Ottawa, 1985. London: PHLS, 1985: 165-6.

24 Ligumsky M, Karmeli F, Rachmilewitz D. Sucralfate stimulation of gastric $\mathrm{PGE}_{2}$ synthesis - possible mechanisms to explain its effective cytoprotective properties. Gastroenterology 1984; 86: 1164.

25 Tytgat GNJ, Rauws E, Langenberg W. The role of colloidal bismuth subcitrate in gastric ulcer and gastritis. Scand J Gastroenterol 1986; 21 (suppl 122): 22-9.

26 Langenberg ML, Rauws EAJ, Schipper MEI, et al. The pathogenic role of Campylobacter pyloridis, studied by attempts to eliminate these organisms. In: Pearson AD, Skirrow MB, Lior H, Rowe B, eds. Campylobacter III: proceedings of the third international workshop on campylobacter infections. Ottawa 1985. London: PHLS, 1985; 162-3.

27 Bader JD. The safety profile of De-Nol. Digestion 1987; 37 (suppl 2): 53-9.

28 Borody T, Hennessy W, Dascalopoulos G, Carrick J, Hazell S. Double-blind trial of De-Nol in non-ulcer dyspepsia associated with Campylobacter pylori gastritis. Gastroenterology 1987; 92: 1324.

29 Lambert JR, Borromeo M, Korman MG, Hansky J. Role of Campylobacter pyloridis in non-ulcer dyspepsia - A randomized controlled trial. Gastroenterology 1987; 92: 1488.

30 Wenger J, Petty AM, Mendeloff J. Simultaneous gastroscopic photographic and histological report. Gastrointest Endosc 1970; 16: 234-6.

31 Joffe JN, Lee FD, Blumgart LH. Duodenitis. Clin Gastroenterol 1978; 7: 635-50.

32 Fung WP, Papadimitriou JM, Matz LR. Endoscopic, histological and ultrastructural correlations in chronic gastritis. Am J Gastroenterol 1979; 71: 269-79.

33 Gregg JA, Garabedian M. Duodenitis. Am J Gastroenterol 1974; 61: 177-84.

34 Myren J, Sereck-Hanssen A. The gastroscopic diagnosis of gastritis with particular reference to mucosal reddening and mucus covering. Scand J Gastroenterol 1974; 9: 457-62. 